\title{
BMJ Open Impact of mothers' employment on infant feeding and care: a qualitative study of the experiences of mothers employed through the Mahatma Gandhi National Rural Employment Guarantee Act
}

\author{
Manisha Nair, ${ }^{1}$ Proochista Ariana, ${ }^{2}$ Premila Webster ${ }^{3}$
}

To cite: Nair M, Ariana $P$, Webster P. Impact of mothers' employment on infant feeding and care: a qualitative study of the experiences of mothers employed through the Mahatma Gandhi National Rural Employment Guarantee Act. BMJ Open 2014;4: e004434. doi:10.1136/ bmjopen-2013-004434

- Prepublication history and additional material is available. To view please visit the journal (http://dx.doi.org/ 10.1136/bmjopen-2013004434).

Received 7 November 2013 Revised 11 March 2014 Accepted 12 March 2014

CrossMark

For numbered affiliations see end of article.

Correspondence to Dr Manisha Nair; manisha.nair@npeu.ox.ac.uk

\section{ABSTRACT}

Objective: To explore the experiences of mothers employed through the Mahatma Gandhi National Rural Employment Guarantee Act (MGNREGA) using focus group discussions (FGDs) to understand the impact of mothers' employment on infant feeding and care. The effects of mothers' employment on nutritional status of children could be variable. It could lead to increased household income, but could also compromise child care and feeding.

Setting: The study was undertaken in the Dungarpur district of Rajasthan, India.

Participants: Mothers of infants $<12$ months of age. Ten FGDs, two in each of the five administrative blocks of the study district were conducted. The groups were composed of a minimum of 5 and maximum of 8 participants, giving a total of 62 mothers. Thematic analysis was conducted to assess patterns and generate emergent themes.

Results: Four major themes were identified-'mothers' employment compromises infant feeding and care', 'caregivers' inability to substitute mothers' care', 'compromises related to childcare and feeding outweigh benefits from MGNREGA' and 'employment as disempowering'. Mothers felt that the comprises to infant care and feeding due to long hours of work, lack of alternative adequate care arrangements, low wages and delayed payments outweighed the benefits from the scheme.

Conclusions: This study provides an account of the trade-off between mothers' employment and child care. It provides an understanding of the household power relationships, societal and cultural factors that modulate the effects of mothers' employment. From the perspective of mothers, it helps to understand the benefits and problems related to providing employment to women with infants in the MGNREGA scheme and make a case to pursue policy changes to improve their working conditions.

\section{Strengths and limitations of this study}

- This study provides an in-depth understanding of the direct and indirect factors that could mediate the effects of mothers' employment through the Mahatma Gandhi National Rural Employment Guarantee Act (MGNREGA) on feeding and care of infants.

- The findings of this study are unique compared to other studies that have assessed the effects of women's employment because it weighs the benefits of providing employment through MGNREGA to mothers with small children in the context of broader social factors.

- This study is the first to highlight issues of mothers being coerced through physical violence by family members to work in the MGNREGA scheme.

- Our study findings may not be generalisable to the country as a whole because the social status of women varies across the states in India and thus the experiences of women may be different.

- Our study participants are mothers with young infants who face a certain set of problems that single/widow/mothers with older children may not face and therefore, their perceptions are likely to be influenced by these unique factors.

\section{BACKGROUND}

Unemployment has been linked to poverty and food insecurity in India ${ }^{1}$ and is an important determinant of infants' nutritional status. While the association between fathers' employment and nutritional status of children is in general beneficial, ${ }^{2}{ }^{3}$ the effects of mothers' employment could be variable. Studies in the 1970s explored the relationship between mothers' participation in the labour market and implications on child nutrition. ${ }^{4}$ Observational studies appear to 
demonstrate that mothers' employment could be detrimental to child nutrition ${ }^{5-8}$ due to their inability to devote adequate time for feeding and care. ${ }^{49}$ The tradeoff between mothers' time spent in earning for the family and time spent in childcare is also influenced by other factors such as availability of other carers, amount earned and a mother's ability to access and utilise her earnings. ${ }^{5} 8{ }^{10}$ However, providing employment to mothers could have a positive effect on household income and their status within the household and society $^{2}$ which has been shown to be an important social determinant of infant nutrition. ${ }^{7} 1112$

The Mahatma Gandhi National Rural Employment Guarantee Act (MGNREGA) is a wage-for-employment scheme of the Government of India which targets deprivation and food insecurity in rural households. ${ }^{13-15} \mathrm{~A}$ salient feature of the scheme is that at least one-third of the beneficiaries should be women. ${ }^{16}$ While MGNREGA is considered successful in providing employment and equal wages to women, ${ }^{17} 18$ it has overlooked the childcare factors related to mothers' employment. The act includes provision for crèche facilities at all worksites, ${ }^{16}$ however, surveys of crèche facilities for mothers employed at MGNREGA worksites in two southern states showed that they are not only inadequate, but in some cases deliberately unfavourable for childcare. ${ }^{18} 19$ This study explored the experiences of mothers employed through MGNREGA to understand the impact of mothers' employment on infant feeding and care.

\section{METHODS}

Focus group discussions (FGDs) were used to explore the experiences of mothers of infants less than 12 months of age. Since the topic was more socially relevant and less sensitive, we used FGDs rather than in-depth interviews. ${ }^{20-22}$ The study was conducted in the Dungarpur district in the Indian state of Rajasthan. Dungarpur is a phase-I district, where MGNREGA has been implemented since September 2006 and according to reports of the Ministry of Rural Development, Government of India, the district was awarded for excellence in MGNREGA implementation. ${ }^{23}$ The FGDs were conducted in two villages (randomly selected) in each of the five administrative blocks of the district. In each village, the venue was the Anganwadi centres (the village Integrated Child Development Services centres). A semistructured guide was used to conduct the FGDs (provided in table 1) which was tested in a pilot study conducted with six mothers.

The sample size for the FGDs was based on expert opinion, published literature and the research question. ${ }^{24}{ }^{25}$ With regard to focus groups the rule of thumb as discussed by Morgan ${ }^{21}$ and Kitzinger, ${ }^{26}$ is three to five groups. However, they also suggest that the number depends on within and across group diversity, structure of the interview guide and the point of saturation of information. ${ }^{21} 26$ Although, 'saturation' was reached after six FGDs, to achieve a fairly high degree of within and across group diversity, 10 focus groups (2 in each of the 5 administrative blocks of the study district) were undertaken. The groups were composed of a minimum of five and maximum of eight participants.

A purposive sampling method was used to recruit participants for the FGDs. The participants were a subset of mothers who participated in a cross-sectional study that analysed the effect of households' participation in MGNREGA on infant malnutrition. ${ }^{27}$ Eleven FGDs (including the pilot study) were conducted with 62 mothers. Although it was planned to segregate the participants based on their employment through MGNREGA to understand the perception of the MGNREGA employed and non-employed mothers, this was not possible. The reason was that not many mothers were found to be employed through MGNREGA during the study period within the selected villages. One-third $(n=19)$ of the total 62 mothers worked in MGNREGA at some point, and over one-quarter $(n=16)$ worked after their delivery and were still employed during the time of the FGDs. Along with the participant IDs for each quote (in the findings section) the employment status of the participants-ever employed through MGNREGA (MGNREGA) or never employed through MGNREGA (non-MGNREGA) is also stated. The perceptions and opinions about the scheme of women who were never employed through MGNREGA were based on either members of their households participating in the scheme or observations about the experiences of other women.

Table 1 Semistructured guide for the focus group discussions

\begin{tabular}{ll}
\hline SI. No. & Question \\
\hline 1 & $\begin{array}{l}\text { Should women be employed/work to earn } \\
\text { money? }\end{array}$ \\
2 & $\begin{array}{l}\text { What could be the effect on babies, especially } \\
\text { less than } 12 \text { months if mothers are employed? }\end{array}$ \\
& Who other than the mother cares for the child?
\end{tabular}

Prompts

Why? Or why not?

MGNREGA-specific issues, anything else?

Baby's father? Grandmother? Relatives? Health provider? Community health worker? Anganwadi worker, ASHA? Anyone else?-How?

This is a section of the topic guide used for the research project. The questions relevant to this study are provided in this table. MGNREGA, Mahatma Gandhi National Rural Employment Guarantee Act. 
While all participants were mothers who had an infant in the age group of 1-12 months, they were significantly different in terms of their level of education (illiterate $=39$; primary education $=17$; secondary and higher education=9), socioeconomic status (lowest 2 quintiles of asset index $=21$; third quintile $=10$; fourth quintile $=14$ and fifth quintile $=19$ ), social groups (44 belonged to the Schedule Tribe/Schedule Caste social groups and 21 were from the non-Schedule Tribe/Schedule Caste groups) and age (the median age was 25 years but ranged from 19 to 40 years).

MGNREGA scheme is usually active in Dungarpur district during the lean agricultural months from October to March. As this study was conducted between August and September (2011), there were not many active MGNREGA worksites. Active worksites were found in only 4 of the 10 villages from which participants were recruited. It was observed that the work involved heavy manual labour and its allocation did not differ by gender, that is, both men and women had to do the same kind of work. The four worksites found were mainly along the highway, where the employed workers (both men and women) were involved in digging trenches on the side of the road to prevent rain water from flooding and damaging the highway. These worksites were found to be within the recommended distance of $5 \mathrm{~km}$ from the village and on an average the workers spent $6-8 \mathrm{~h}$ on the site, as reported by the site-supervisors. There were no crèche facilities at the observed sites and only one or two children were seen at these sites.

The FGDs were conducted by MN with the help of a field assistant. $\mathrm{MN}$ is trained in qualitative research methods and has experience in facilitating FGDs. The field assistant was a trained local female nurse who acted as the translator and also took notes during the discussion. A memo was maintained by $\mathrm{MN}$, and after consent was obtained all FGDs were recorded using an audio recorder for maximum transparency.

The audio tapes were transcribed non-verbatim, translated to English and cross-checked with the field notes. Employing the method of thematic analysis, ${ }^{21} 28$ the transcripts and memos were coded to assess patterns in the information collected in order to generate set themes (based on literature) and emergent themes. The transcripts and codes were managed using NVivo9. ${ }^{29}$ Thick descriptions on group dynamics and interactions were used to clearly state the context of the FGDs. ${ }^{30}$ It was not possible to have a second researcher code the transcripts, however, the codes and the themes were checked by the two coauthors. It was also not possible to do a 'member-checking' to ensure validity of the reported themes, ${ }^{31}$ but a short summary of the discussions was presented at the end of each FGD to check if the views of the participants were captured accurately.

A major challenge faced during the FGDs was initiating discussions among the participants. The women were reluctant to speak and had their faces covered. To overcome this problem and to make the participants comfortable, the local village nurse was also allowed to be present during the discussions. This resulted in some prompting by the nurse. However, these prompts were noted in the memos and were taken into consideration while analysing the themes. Despite such measures, it was observed that one or two participants (usually the educated) dominated the discussions and a few (mainly young and illiterate women) did not speak at all but simply nodded their heads.

\section{FINDINGS}

The transcripts were first coded to generate set themes on 'mothers' employment and infant feeding', 'mothers' employment and infant care', 'caregivers other than the mother and mothers' perception of other caregivers'. Several patterns emerged, which were grouped into two main themes-'mothers' employment compromises infant feeding and care' and 'caregivers' inability to substitute mothers' care'. In addition, a number of themes emerged related to the perceptions of the mothers about actual benefits of being employed through MGNREGA considering child care issues. These were grouped as benefits from MGNREGA versus issues of child care. In the second FGD one woman mentioned that they were forced to work and were being beaten and forced by their husbands and mothers-in-law to work in MGNREGA. Following this, other groups were probed to get a more in-depth understanding of this issue and if the purported 'physical violence' was associated with women's employment in MGNREGA, although this was not an original theme. Analysis of the information collected on coercion through physical violence highlighted several issues which led to the fourth theme 'employment as disempowering'.

The participants' views grouped under each theme were in general found to follow a common pattern; however, there were some conflicting views about quality of care provided by other carers and the presumed benefits of crèche facilities at work sites. The themes were constructed based on what most women said, but the conflicting comments are discussed under each theme. It is also important to highlight that the findings presented in this study differs from that of the other paper published from the research project that analysed the effect of households' participation in MGNREGA on infant malnutrition. ${ }^{27}$ While the previous paper was in the context of households receiving employment through the MGNREGA scheme, irrespective of who was employed, and its impact on infant nutrition, this paper focuses on perceptions of mothers of infants regarding employment through the MGNREGA.

\section{Mother's employment compromises infant feeding and care}

The participants said that mothers' employment in MGNREGA led to compromises in infant feeding and care. This was mainly related by mothers employed through MGNREGA during the study period who 
started work between 3 and 6 months after giving birth and by participants who opted out due to such experiences with their previous child. They complained about problems with breastfeeding their infants during work hours which compromised both timely feeding and exclusive breastfeeding. The work sites were sometimes far from the village and long hours of work made it difficult for them to come home to feed the child even during their lunch break. This left the child hungry and in distress.

Even if [we] get a little time, [we] come home and feed the child. Tell them [the supervisors], then run and come and feed the child. (M-60; MGNREGA)

[We can come home] if the work place is near, if far cannot [come], then [we] breastfeed only when the day is over. (M-48; MGNREGA)

The mothers employed in MGNREGA faced physical problems such as pain and swelling of their breasts due to not being able to feed their child for long hours. They were also anxious and worried about their child.

Milk accumulates in the breast; it swells and is painful when I don't feed the child from time to time. It happens when I am away for a long time. (M-47; MGNREGA)

Yes, we have problems in leaving the child at home, Even if we go we have problems, we are worried about the child. Our mind and heart are with the child. (M-55; MGNREGA)

Although the policy guidelines of MGNREGA state it is mandatory for all work sites with five or more children below 6 years of age to provide crèche facilities, such provisions were not available in the communities surveyed. While some women felt that provision of crèche facilities at the work site would address the problems related to infant feeding, others were concerned about the safety of their children at the work sites and therefore, did not feel that crèche facilities would make any difference.

[If crèche facilities are available] our breast will not swell, we can feed the child from time to time. (M-15; MGNREGA)

No we will not take the child, he is safe at home in the shade. Don't know how another woman will keep him, he is safe at home. (M-25; non-MGNREGA)

It is hot, where do we keep the child? We do just this kind of work [manual labour] which is not safe, where will we keep the child? (M-27; MGNREGA)

Thus, it appears that mothers' employment in MGNREGA was detrimental to infant feeding and to their own well-being. The mandatory provision of crèche facilities at worksites appeared to exist only on paper and mothers had to spend a considerable time away from infant feeding and care.

\section{Caregivers' inability to substitute mothers' care}

During the MGNREGA work hours, the infant was taken care of by another family member, usually the paternal grandmother of the child (mother-in-law of the woman). There were different perceptions among the mothers about care provided by other carers. While some study participants believed that their mothers-in-law took good care of the infant in their absence, others did not trust them and yet others did not know.

We have faith in her [mother-in-law] that is why we leave the child with her. (M-27; MGNREGA)

Who will take care of a child like a mother does? My mother-in-law works in the house, cooks roti (bread), washes clothes, does other work. She just lays down the child somewhere on the floor. (M-21; non-MGNREGA)

A mother who was employed through MGNREGA complained that her mother-in-law only pretended to take care of the child in order to force her to work. Another participant mentioned that the mothers employed through MGNREGA had no choice but to leave their children with other caregivers irrespective of whether the children were taken care of or not.

She [mother-in-law] does not take care of the child, but when she sees me coming home, she will pretend to take care of the baby otherwise she thinks that I will not go for work the next day and not bring home money. (M-08; MGNREGA)

How do we know? Whether [she] takes care or not, we leave the child and go. (M-44; MGNREGA)

Although some women knew that their children were neglected by the other caregivers and were not provided with timely and adequate feeding, they found themselves helpless due to the necessity to earn money and lack of child care facilities at the work sites.

Child is in distress, but so what, we have to go. (M-26; MGNREGA)

Although, women were doubtful about the benefits of the crèche facilities at the worksite, it seems that the options of care available at home were not always acceptable or adequate.

\section{Compromises related to childcare and feeding outweigh benefits from MGNREGA}

Providing employment to women was generally considered beneficial for economic and social well-being of the family. As discussed in the earlier paper, ${ }^{27}$ providing employment to rural households had a cumulative positive effect on infant nutrition mainly by preventing 
hunger. However, the perceptions of the mothers in this study were mainly related to compromises in the time devoted by the mother to child care and feeding, and lack of adequate care by other caregivers. The study participants were of the opinion that the benefits received from participating in MGNREGA were not worth the compromises to child care and feeding related to employment. In addition, they had to face the problems of delayed payment and low wages. This resulted in many women with young children to opt out of MGNREGA.

We think, what do we earn after leaving the child at home, but what can we do, we have to go to work. (M-44; MGNREGA)

I used to go before, not now. What is the use when we get the money so late? I don't go, if the child is sick, from where will I get money for his treatment? (M-58; MGNREGA)

It appears that providing employment to mothers through MGNREGA led to compromises in infant care and feeding among the study participants. Thus many women preferred not to seek employment after their delivery, but some did not have a choice. There appeared to be a consensus that benefits from MGNREGA were not substantial for the mothers to leave their young children without adequate care arrangements.

Don't get any benefit. I leave the child crying at home and go and don't get anything. Don't get money, if I work now I will get money 1 year later. What is the use of going? (M-19; MGNREGA)

\section{Employment as disempowering}

While it is generally believed that providing employment would provide women with financial independence and lead to empowerment, this was not found to be the case among the study participants. None of the participants mentioned employment through MGNREGA as being essential for the women's financial independence and empowerment. This can perhaps be explained by the reasons given by the participants for working in MGNREGA and how their earnings were used. There were three reasons found for women's participation in MGNREGA: self-motivation, forced to work and no other option.

The need to earn money for the household and for their own survival was the motivation cited by some women for working in MGNREGA.

Who will give me food if I keep sitting [at home]? (M-51; MGNREGA)

Women being beaten up and coerced to work in MGNREGA was a major reason for the women's participation in MGNREGA. It was striking to observe that almost all women spoke about coercion, some explicitly, some by agreeing to what the fellow participants said and others by smiling and nodding when probed.

If I go they beat me less, if I don't go they beat me a lot. (M-15; MGNREGA)

\begin{abstract}
Mother-in-law sends us, she says go and work, everyone else is working. We will keep the young child, you go, they say. We have to go. [We] have swelling of the breast and pain, but what can we do? We have to go. Come back home only when they [supervisors] give us leave for the day. (M-44; MGNREGA)
\end{abstract}

During the FGDs women not only narrated their experiences, but also gave several examples of other women who faced similar problems. They probed each other to tell their stories. One woman probed a fellow participant who was reluctant to speak:

Why don't you tell her (the facilitator) what happened to you? Why are you scared? Your mother-in-law is not here. (M-34; non-MGNREGA)

This reflects the social status of the women in the study district and alludes to their helplessness. Women were not free to decide whether they wanted to work or not, it was the family members (in-laws and husband) who decided and in most cases used force and violence to make them work. Some women mentioned that they had to go to work in MGNREGA because there was no other option. Owing to the reservation of a third of the jobs for women in MGNREGA, it is easier for the women in the house to get the job. Women with young children often did not work if their mothers-in-law were able to replace them, but if there was no other female member capable of working in MGNREGA they were forced to go because of their economic circumstances and pressure from the family members (in-laws and/or husband).

[I] have to go to work, my mother-in-law is sick, if I don't go my boy will die of hunger. If we earn we can feed, so we have to go, [we] have to understand and go. (M-52; MGNREGA)

Further, the women were not allowed to use their earnings on what they thought was important or useful. They had to give their earnings to the household head (either father-in-law or mother-in-law) and had to depend on them to get even a small sum to spend from their own earnings.

We give it to our mother-in-law, she buys the daily household goods, we get a little from her to spend. (M-55; MGNREGA)

No we cannot keep any, if we keep money they [mother-in-law and father-in-law] say you have money so run the house. How can we run the whole [house]? (M-44; MGNREGA) 
The small amount of money that they received was mostly spent on small personal things such as bangles and to buy biscuits for their infants. There was no mention about using the mothers' earnings for healthcare or for savings. Thus, it appears that employment of mothers through MGNREGA in addition to leading to compromises in infant care and feeding was also a means of oppressing the women. Low social status and oppression did not allow women to take independent decisions about spending their own earnings. Under such circumstances, it is unlikely that employment through MGNREGA could lead to women's empowerment in the study population.

\section{DISCUSSION}

Mothers' employment through MGNREGA appears to compromise infant feeding and care. Mothers felt that the compromises to infant care and feeding due to long hours of work, lack of alternative adequate care arrangements, low wages and delayed payments outweighed the benefits from the scheme. Mothers with young infants were coerced and beaten to work in MGNREGA by household members and thus often became victims of domestic violence which could further compromise infant feeding and care.

Our study findings are in general different from the findings of other studies which showed that the prowomen feature of MGNREGA has improved women's participation in the scheme and has conferred financial security and independence, ${ }^{17}$ 32-36 except for a study among women in southern India that highlighted similar problems. ${ }^{19}$ Two qualitative studies, one from the state of Odisha $^{33}$ and another from Haryana ${ }^{34}$ suggested that MGNREGA has been successful in providing financial independence, confidence and security to women and they are able to independently make decisions about spending their earnings. However, the Haryana study highlighted that the bank accounts where the wages are paid are mostly in the names of their husband or another male member, and the women have to rely on them to withdraw the wages. ${ }^{34}$ Under such circumstances, financial independence is unlikely. In addition, the authors noted that awareness about the entitlements under the MGNREGA scheme is low among women and as a consequence many women do not get the guaranteed 100 days of employment or related unemployment allowance. ${ }^{34}$ They also reported that women opt out from MGNREGA due to delayed payments, lack of crèche facilities and unfavourable working conditions. ${ }^{34}$ However, it is not known if the women who opt out are the ones with young children. The findings of this study could be different because of the difference in the sample population. This study specifically included mothers with infants compared to women in general in the other studies. Mothers with infants and young children are likely to face a certain set of problems that single women, widows and women without young children may not face.
While studies suggest that availability of other carers at home could minimise the negative effects of mothers' employment on child care and nutrition, ${ }^{10}$ the findings of this study suggest that some mothers did not trust the other caregivers, who were mainly their mothers-in-law, and perceived the care provided to be inadequate. A qualitative study in western Kenya suggested that the relationship between mothers' employment and child nutrition is influenced by household factors that necessitate mothers' employment (such as low income and deprivation), and the knowledge and attitude of other caregivers who compensate for the mothers' time away from childcare. ${ }^{35}$ It was suggested that in addition to mothers, the other caregivers (mainly the grandmother and the child's father) should be educated about adequate child feeding and care practices. ${ }^{35}$

It is possible that compromises in infant feeding and care would exist for mothers who work as agricultural labourers or on their own farm, making mothers' employment in general a critical contributing factor to infant malnutrition, particularly in the absence of adequate crèche facilities. However, the problem in case of this employment scheme is made worse by long hours of work and fixed work sites for a village which may or may not be at a convenient distance for the mothers to come home and feed the children. Data from two large cohorts, from Britain and the USA, suggest that the negative effects of mothers' employment on child health and development could be offset by provisions of adequate maternity leaves and part-time employment for mothers with young children. ${ }^{36}$ While some studies suggested that providing crèche facilities at MGNREGA work sites could ensure that the mothers are able to spend more time caring for and feeding their young children, ${ }^{19}$ the participants in this study had mixed views about the utility of crèche facilities even if they were available. To ensure greater benefits, in addition to providing child-care facilities at MGNREGA worksites, it would be useful for women with infants and young children to have two to three feeding breaks and the work sites should be closer to the villages. The recommended distance for work sites, which is within $5 \mathrm{~km}$ from the worker's residence, may be too far for a mother to travel to feed her infant in the absence of quality crèche facilities. She will have to walk $10 \mathrm{~km}$ two or three times during the day.

Research suggests that employment can lead to empowerment of women through financial independence and security which in turn could have a positive impact on child health and well-being. ${ }^{37}$ The goal of the MGNREGA is to provide employment to empower the rural poor. The reasons for women's participation in MGNREGA are suggested to be: employment opportunities at the 'doorstep', non-requirement of specific skills, female supervisors and equal wage rates for men and women. ${ }^{17}$ In contrast, this study showed that the reasons for participation of mothers of infants may not always be positive. Financial need of the households and the 
policy of favouring women compel mothers with infants to participate in MGNREGA despite the hardships they face and the compromises to infant feeding and care. This is either self-selected due to economic reasons or imposed by their family members, perhaps again due to economic needs, in some cases through violence which could have negative effects on child care and feeding. In addition to the evident physical harms of domestic violence, studies show that women who experience domestic violence have higher levels of psychological stress ${ }^{38}$ and are unable to make day-to-day decisions about feeding and care of their children and themselves. ${ }^{7}$

The women in this study were neither allowed to keep their earnings nor had the autonomy to spend their own earnings, an issue that was noted in another qualitative study on MGNREGA, but not discussed in depth. ${ }^{17}$ Pankaj and Tankha ${ }^{17}$ in their study showed that about $50 \%$ of the women employed through MGNREGA in Dungarpur district were able to retain $25 \%$ of their earnings, $30 \%$ women could retain none and only $20 \%$ women retained $51-100 \%$ of their earnings from MGNREGA. They reported similar figures for three other districts from the northern and eastern parts of India. The authors commented that this is better than nothing and hoped that the situation will improve over time. ${ }^{17}$ Another study in India (not related to MGNREGA) has also highlighted women's inability to retain their earnings as a major obstacle to realising the benefits of women employment. ${ }^{5}$ Although employment in MGNREGA has provided women in our study population with some earnings to meet minor personal needs it appears that employment through MGNREGA could be a source of oppression. However, it is acknowledged that these findings are very much attributable to the societal context, social status of women and levels of female literacy and thus will differ across the states in India. Merely providing employment to women may not lead to their financial independence or empowerment, unless their status within the household and society at large is improved. Unless mothers have the power to decide on the utilisation of their earnings from any source, it is not likely that their earnings will be used to benefit themselves or their children. The issues related to coercion and violence against women and their oppression will require efforts from various sectors to bring about a social change both through formal and informal education of women and their partners.

\section{Limitations}

A third of the participants were employed through MGNREGA and it is possible that others not included in this study may have different experiences and perceptions about the advantages and disadvantages of mothers' employment through MGNREGA and its impact on infant care and feeding. Further, the social and cultural issues related to women's employment and their social status in Rajasthan is different from that in the southern and eastern states in India. In general,
Rajasthan has reported problems of female infanticide, child marriage and low education status of women. The experiences of women related to employment through MGNREGA could be different in other Indian states. Nevertheless, it is important to pay due consideration to the issues raised by the participants in this study. It is possible that the same issues could be identified in some of the more deprived states in India where the educational status of women and their social status are similar to that in Rajasthan.

\section{Conclusion}

Women in India are an important part of the economic sector and the reproductive age of women (15-44 years) overlaps their economically productive age (15-59 years) ${ }^{39}$ According to the 2001 census, there are an estimated 233.7 million women in the age group of 1544 years which constitutes approximately $47 \%$ of the total female population. ${ }^{39}$ While, MGNREGA reserves $33 \%$ of the person-days of work for women, in the financial year 2012-2013, 52\% (983 million) of the total person-days generated were provided to women. ${ }^{40}$ It is most likely that a majority of them are in their reproductive age. Thus, studies are required to analyse the trade-off between mothers' employment and child care to gain a true understanding of the benefits and problems related to providing employment to women with young children in the MGNREGA scheme. Such studies will enable policy makers to package the provision of women's employment in MGNREGA in a more effective manner taking account of the social factors and their child care responsibilities.

The objective of this study was to understand the experiences of mothers' employment through MGNREGA and its possible impact on infant feeding and care. There appears to be several issues that could have a negative effect such as lack of crèche facilities, unfavourable working conditions and coercion. However, this does not imply that women with young children should not be employed through the scheme. Women are an important part of the workforce and programmes such as MGNREGA should pay special attention to issues of mothers' employment within the context of 'women employment'. While a number of studies analysed the benefits of providing employment to women through the MGNREGA, this is the first to focus on the experiences of mothers with infants. It is important that mothers' employment should be an integral part of MGNREGA evaluation to ensure that appropriate changes could be made to the policy to improve the working conditions for mothers with infants.

\section{Author affiliations}

${ }^{1}$ National Perinatal Epidemiology Unit (NPEU), Nuffield Department of Population Health, University of Oxford, Oxford, Oxfordshire, UK

${ }^{2}$ Nuffield Department of Population Health and Department of International Development, University of Oxford, Oxford, UK

${ }^{3}$ Nuffield Department of Population Health, University of Oxford, Oxford, Oxford, UK 
Contributors MN designed the study, conducted the field research, analysed the data and wrote the manuscript. PA and PW contributed towards the study design and data analysis, and edited the manuscript. All authors approved the final version.

Funding This work was supported by the University of Oxford and Weidenfeld Scholarship and Leadership Programme.

Competing interests None.

Ethics approval University of Oxford Tropical Research Ethics Committee (OXTREC); OXTREC Reference: 43-11 and Directorate of Medical, Health and Family Welfare Services, Government of Rajasthan.

Provenance and peer review Not commissioned; externally peer reviewed.

Data sharing statement No additional data are available.

Open Access This is an Open Access article distributed in accordance with the Creative Commons Attribution Non Commercial (CC BY-NC 3.0) license, which permits others to distribute, remix, adapt, build upon this work noncommercially, and license their derivative works on different terms, provided the original work is properly cited and the use is non-commercial. See: http:// creativecommons.org/licenses/by-nc/3.0/

\section{REFERENCES}

1. Planning Commission; Government of India. 9th Five Year Plan vol.2. New Delhi. http://planningcommission.gov.in/plans/planrel/ fiveyr/9th/vol2/v2c2-1.htm (accessed 23 Mar 2011).

2. Engle PL. Influences of mothers' and fathers' income on children's nutritional status in Guatemala. Soc Sci Med 1993;37:1303-12.

3. Vella V, Tomkins A, Borghesi A, et al. Determinants of child nutrition and mortality in north-west Uganda. Bull World Health Organ 1992;70:637-43.

4. Popkin BM, Solon FS. Income, time, the working mother and child nutriture. Environ Child Health 1976;22:156-66.

5. Abbi R, Christian P, Gujral S, et al. The impact of maternal work status on the nutrition and health status of children. Food Nutr Bull 1991;13:20-5.

6. Choudhary M, Jain S, Saini V. Nutritional status of children of working mothers. Indian Pediatr 1986;23:267-70.

7. Sethuraman K, Lansdown R, Sullivan K. Women's empowerment and domestic violence: the role of sociocultural determinants in maternal and child undernutrition in tribal and rural communities in South India. Food Nutr Bull 2006;27:128-43.

8. Lamontagne JF, Engle PL, Zeitlin MF. Maternal employment, child care, and nutritional status of 12-18-month-old children in Managua, Nicaragua. Soc Sci Med 1998;46:403-14.

9. Brush G, Harrison G, Zumrawi F. A path analysis of some determinants of infant growth in Khartoum. Ann Hum Biol 1993:20:381-7.

10. Bennett $\mathrm{L}$. The role of women in income production and intra-household allocation of resources as a determinant of child nutrition and health. Food Nutr Bull 1988;10:16-26.

11. Shroff M, Griffiths $P$, Adair L, et al. Maternal autonomy is inversely related to child stunting in Andhra Pradesh, India. Maternal Child Nutr 2009;5:64-74.

12. Shroff MR, Griffiths PL, Suchindran C, et al. Does maternal autonomy influence feeding practices and infant growth in rural India? Soc Sci Med 2011;73:447-55.

13. Menon SV. Right To Information Act and NREGA: reflections on Rajasthan. Munich Personal RePEc Archive 2008 [Report]. http:// mpra.ub.uni-muenchen.de/7351/ (accessed 21 Mar 2011.

14. Centre for Science and Environment; New Delhi. The National Rura Employment Guarantee Act (NREGA) opportunities and challenges. Discussion paper. New Delhi: CSE, 2008.

15. Ministry of Rural Development; Government of India. Mahatma Gandhi National Rural Employment Guarantee Act, 2005: report to the people 2nd February 2012. New Delhi: Department of Rural
Development, Ministry of Rural Development; Government of India, 2012.

16. The National Rural Employment Guarantee Act. 2005, (5 September 2005).

17. Pankaj A, Tankha R. Empowerment effects of the NREGS on women workers: a study in four states. Econ Polit Wkly 2010;45:45-55

18. Narayanan S. Employment guarantee, women's work and childcare. Econ Polit Wkly 2008;43:10-13.

19. Uppal V. Is the NREGS a safety net for children? (Young Lives student paper). Oxford: University of Oxford, 2009.

20. Kitzinger J. Qualitative research: introducing focus groups. BMJ 1995;311:299

21. Morgan DL. Focus groups as qualitative research. 2nd edn. Thousand Oaks, CA: Sage publications, 1997.

22. Wutich A, Lant T, White DD, et al. Comparing focus groups and individual responses on sensitive topics: a study of water decision makers in desert city Field Methods. 2010;22:88-110.

23. Ministry of Rural Development; Government of India. Mahatma Gandhi National Rural Employment Guarantee Act 2005: report to the people 2nd February 2006-2nd February 2010. New Delhi: Department of Rural Development, 2010.

24. Teddlie C, Tashakkori A. Foundations of mixed methods research Integrating quantitative and qualitative approaches in the social and behavioural sciences. Thousand Oaks, CA: Sage, 2009.

25. Creswell JW, PlanoClark VL. Designing and conducting mixed methods research. 2nd edn. Thousand Oaks, CA: Sage, 2011.

26. Kitzinger J. Introducing focus groups. BMJ 1995;311:299-302.

27. Nair M, Ariana P, Ohuma EO, et al. Effect of the Mahatma Gandhi National Rural Employment Guarantee Act (MGNREGA) on malnutrition of infants in Rajasthan, India: a mixed methods study. PLOS ONE 2013;8:e75089.

28. Boyatzis RE. Transforming qualitative information: thematic analysis and code development. Sage, 1998.

29. NVivo Qualitative data analysis software. QSR International Pty Ltd: Version 92010

30. Kitzinger J. The methodology of focus groups: the importance of interaction between research participants. Sociol Health IIIn 1994:16:103-21.

31. Creswell JW, Miller DL. Determining validity in qualitative inquiry. Theory Pract 2000;39:124-30.

32. Khera R, Nayak N. Women workers and perceptions of the National Rural Employment Guarantee Act in India. In: Khera R, ed. The battle for employment guarantee. New Delhi, India: Oxford University Press, 2011:81-104.

33. S K. empowerment of women through MGNREGS: issues and challenges (Odisha review) 2013. http://orissa.gov.in/e-magazine/ Orissareview/2013/Feb-Mar/engpdf/76-80.pdf (accessed 7 Oct 2013)

34. Arora V, Kulshreshtha L, Upadhyay V. Mahatma Gandhi National Rural Employment Guarantee Scheme: a unique scheme for Indian rural women. Int J Econ Pract Theories 2013;3:e-ISSN 2247-7225.

35. Whyte SR, Kariuki PW. Malnutrition and gender relations in Western Kenya. Health Transition Rev 1991:1:171-87.

36. Cooksey E, Joshi H, Verropoulou G. Does mothers' employment affect children's development? Evidence from the children of the British 1970 Birth Cohort and the American NLSY79. Longitudinal Life Course Stud 2009;1:95-115.

37. Charmarbagwala $\mathrm{R}$, Ranger $\mathrm{M}$, Waddington $\mathrm{H}$, et al. The determinants of child health and nutrition: a meta-analysis: World Bank. 2004. http://ieg.worldbankgroup.org/Data/reports/ child health nutrition.pdf

38. Briere J, Jordan CE. Violence against women. J Interpers Violence 2004;19:1252-76.

39. Planning Commission; Government of India. Tenth five year plan 2002-2007: sectoral policies and programmes. New Delhi: Planning Commission, Government of India, 2002.

40. Ministry of Rural Development; Government of India (2005) The Mahatma Gandhi National Rural Employment Gurantee Act 2005. New Delhi: Ministry of Rural Development; Government of India. http://nrega.nic.in/netnrega/home.aspx (accessed 10 Jan 2013). 